\title{
Clinical characteristics and factors related to antibiotic-associated diarrhea in elderly patients with pneumonia: a retrospective cohort study
}

Yoko Takedani ${ }^{1}$, Tsukasa Nakamura ${ }^{2,3}$, Noriko Fukiwake ${ }^{1}$, Toshihiro Imada', Junji Mashino ${ }^{1,3}$ and Takeshi Morimoto $3,4^{*}$

\begin{abstract}
Background: Antibiotic-associated diarrhea (AAD) is a common problem among elderly inpatients because many elderly patients are admitted for pneumonia or other conditions that necessitate antibiotic treatment. In the super aging population, more patients are suffering from pneumonia than before, but the incidence or risk factors for AAD among many elderly patients have not been well scrutinized.

Methods: We conducted a retrospective cohort study of elderly patients diagnosed with pneumonia from April 2014 to March 2019 who were admitted to the Department of General Medicine of a Tertiary Care Hospital in Japan. Patients ( $\geq 65$ years of age) who were diagnosed with bacterial pneumonia or aspiration pneumonia and treated with antibiotics were included. We defined AAD by diarrhea with more than three loose or watery stools per day and included patients who had these symptoms for either one day or two or more consecutive days. We also assessed the length of hospital stay and in-hospital mortality. The potential risk factors for AAD included age, sex, body weight, body mass index, smoking, alcohol, activities of daily living (ADL), comorbidities, vital signs, laboratories, the severity of pneumonia, antibiotic and other medication use.

Results: There were 1,067 patients, the mean age was 83 years, and men accounted for $59 \%$. $\beta$-Lactamase inhibitors were frequently prescribed antibiotics in 703 patients (66\%), and proton pump inhibitors (PPIs) were also commonly administered (48\%). AAD developed in 322 patients (30\%). The multivariate logistic regression model showed that $\beta$-lactamase inhibitors (OR 1.43, $95 \% \mathrm{Cl} 1.05-1.95)$ and PPIs (OR 1.37, $95 \% \mathrm{Cl} 1.03-1.83$ ) were associated with AAD as well as age (OR 1.03 per year, $95 \% \mathrm{Cl} 1.01-1.05$ ).

Conclusions: AAD was common among elderly inpatients with pneumonia, and $\beta$-lactamase inhibitors and PPIs were associated with AAD. Strict use of such medication should be considered to decrease the risk of AAD.
\end{abstract}

Keywords: Antibiotic-Associated Diarrhea (AAD), $\beta$-Lactamase Inhibitor, Proton Pump Inhibitor (PPI)

\footnotetext{
* Correspondence: morimoto@kuhp.kyoto-u.ac.jp

${ }^{3}$ Clinical Education and Research Center, Shimane Prefectural Central Hospital, Izumo, Japan

${ }^{4}$ Department of Clinical Epidemiology, Hyogo College of Medicine, 1-1 Mukogawa, Hyogo 663-8501 Nishinomiya, Japan

Full list of author information is available at the end of the article
}

(c) The Author(s). 2021 Open Access This article is licensed under a Creative Commons Attribution 4.0 International License, which permits use, sharing, adaptation, distribution and reproduction in any medium or format, as long as you give appropriate credit to the original author(s) and the source, provide a link to the Creative Commons licence, and indicate if changes were made. The images or other third party material in this article are included in the article's Creative Commons licence, unless indicated otherwise in a credit line to the material. If material is not included in the article's Creative Commons licence and your intended use is not permitted by statutory regulation or exceeds the permitted use, you will need to obtain permission directly from the copyright holder. To view a copy of this licence, visit http://creativecommons.org/licenses/by/4.0/. The Creative Commons Public Domain Dedication waiver (http://creativecommons.org/publicdomain/zero/1.0/) applies to the data made available in this article, unless otherwise stated in a credit line to the data. 


\section{Background}

The incidence of pneumonia is high among elderly patients, especially those elder than 75 years [1]. Aspiration pneumonia is especially common among the elderly, and $\beta$-lactamase inhibitors are frequently prescribed, which have antibacterial activity against anaerobic bacteria [2]. $\beta$-Lactamase inhibitors have been reported to have several adverse effects, and diarrhea is one of the most common adverse effects [3].

Diarrhea occurring after the administration of antibiotics is defined as antibiotic-associated diarrhea (AAD), and Clostridium difficile is the most common pathogen of AAD [4]. AAD frequently develops in the elderly population, and antibiotics with a broad spectrum or strong antibacterial activity against anaerobic bacteria were reported as risk factors for AAD [5]. Therefore, elderly patients with pneumonia who are treated with $\beta$ lactamase inhibitors have an especially high risk for AAD. Once AAD occurs, it results in not only additional treatment but also an extended hospital stay and extra costs [6-8]. Although several studies have reported factors related to AAD, evidence is scant among the elderly and of the association of $\beta$-lactamase inhibitors and AAD. We thus investigated the epidemiology of AAD among elderly patients with pneumonia and explored the clinical characteristics associated with AAD to improve the practice of pneumonia for the elderly considering the risk for AAD.

\section{Methods}

\section{Study design and patients}

We conducted a retrospective cohort study of elderly patients diagnosed with pneumonia from April 2014 to March 2019 who were admitted to the Department of General Medicine of Shimane Prefectural Central Hospital, a tertiary care hospital in Japan. Patients aged 65 years and older who were diagnosed with bacterial pneumonia or aspiration pneumonia and treated with antibiotics were included. The exclusion criteria were patients with (1) viral pneumonia, interstitial pneumonia caused by collagen diseases or other causes, eosinophilic pneumonia, atypical pneumonia, fungal pneumonia and tuberculosis, (2) respiratory infections other than pneumonia such as upper respiratory infections or bronchitis, or (3) diarrhea before admission or transfer from other departments.

We retrieved clinical data, laboratory data and the outcomes of the eligible patients from the Integrated Intelligent Management System (IIMS), which is the unified database that stores the data of electronic medical records, images, ordering system, and other hospital information. The Ethics Review Board of Shimane Prefectural Central Hospital approved this study (approval number: R19-022). Because all data were obtained as a part of routine daily practice, informed consent was waived by the Ethics Review Board of Shimane Prefectural Central Hospital in accordance with the guidelines of the Ministry of Health, Labor and Welfare of Japan.

\section{Measurements}

The retrieved data included age, sex, body weight, body mass index (BMI), history of smoking, alcohol habits, activities of daily living (ADL), comorbidities, vital signs, laboratory date, the severity of pneumonia by CURB 65 score [9], antibiotic use, drug use, microbial test practice. ADL was classified according to ambulatory, bedridden, and whether oral nutrition was provided. Comorbidities contained diabetes mellitus, hypertension, cerebrovascular diseases, ischemic heart disease, heart failure, chronic obstructive pulmonary disease (COPD), chronic kidney disease (CDK), dementia, and cancer. Vital signs contained body temperature, blood pressure, heart rate, and respiratory rate. Laboratory data contained white blood cell, hemoglobin, platelet cell, total protein, albumin, blood urea nitrogen, creatinine, and C-reactive protein on admission. Antibiotics were classified according to whether they contained $\beta$-lactamase inhibitors such as sulbactam or tazobactam. If multiple antibiotics were used, the antibiotics that were used first and contributed most to pneumonia treatment were noted. Drug use contained proton pump inhibitor (PPI), immunosuppressant, angiotensin II receptor blocker, angiotensin converting enzyme inhibitor, calcium channel blocker, beta-blocker, psychotropic, and drug for hyperuricemia.

The primary outcome of this study was AAD. We retrieved stool characteristics and the number of bowel movements from the standard form on the IIMS, which were required to fill out by all nurses in charge (Fig. 1). We defined AAD by diarrhea with more than three loose or watery stools per day and included patients who had these symptoms for either one day [10] or two or more consecutive days $[5,11$, 12]. We also assessed the length of hospital stay and in-hospital mortality. If patients were transferred to other departments or hospitals or died during admission, the length of hospital stay was defined as days from admission to discharge from the Department of General Medicine or time of death during admission to the Department of General Medicine. In-hospital mortality was also limited in the Department of General Medicine.

\section{Statistical analyses}

Continuous variables are presented as the mean and standard deviation (SD) or median and interquartile range (IQR), and categorical variables are presented as 


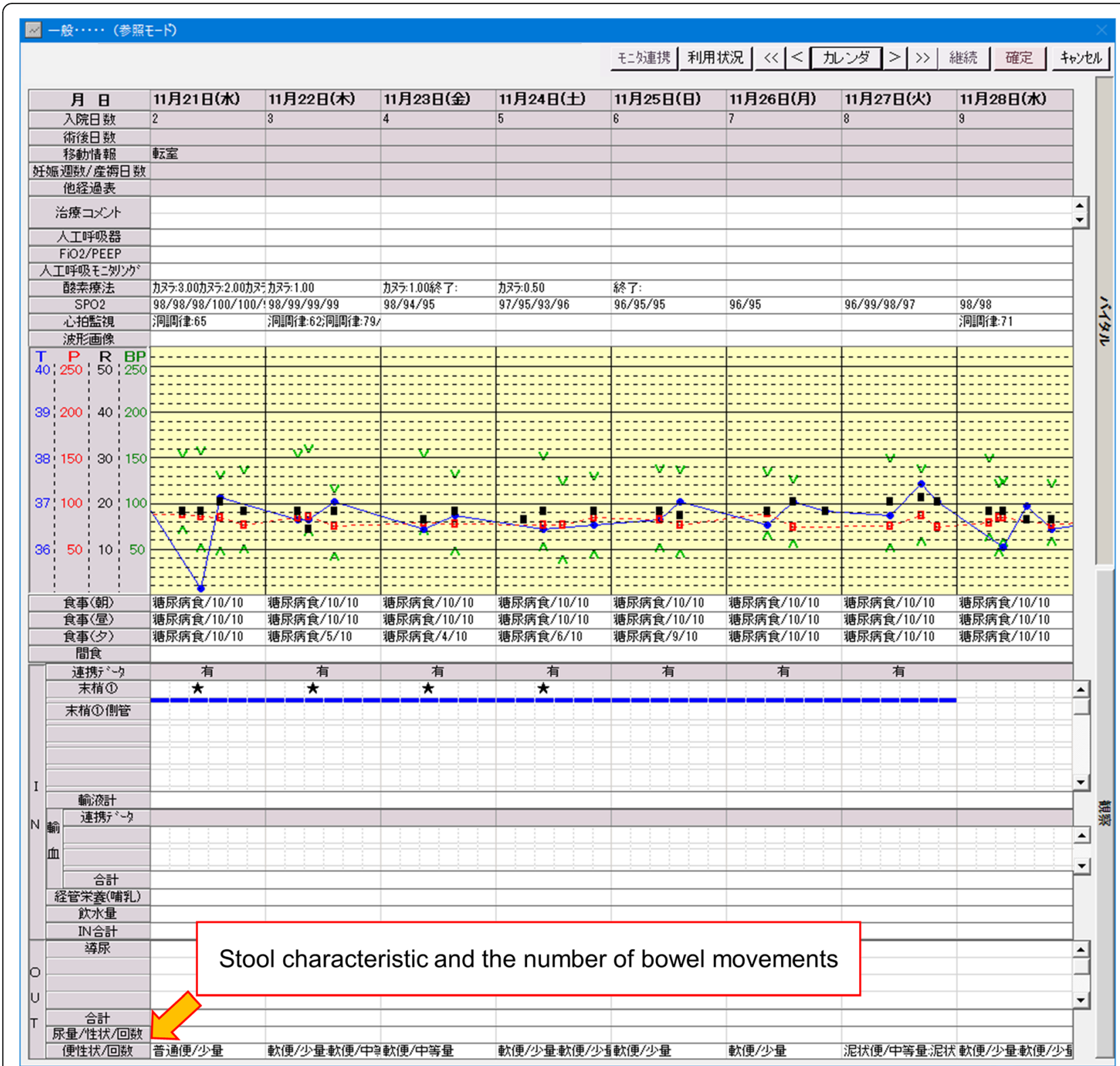

Fig. 1 The example of nursing log with diarrhea record. All nurses require to fill out stool characteristicand the number of bowel movements in the Integrated Intelligent ManagementSystem

numbers and percentages. To explore the factors associated with $\mathrm{AAD}$, we compared continuous variables with Student's $t$ test or the Wilcoxon rank-sum test on the basis of the distributions between patients with and without AAD. We compared categorical variables with the $x^{2}$ test between patient groups. We then constructed multivariate logistic regression models. We simultaneously included variables with significant univariable associations with AAD in the multivariate models. Associations were expressed with odds ratios (ORs) and $95 \%$ confidence intervals (CIs). All reported $p$-values were two-tailed, and $p$-values $<0.05$ were considered statistically significant. All statistical analyses were performed using Stata 14 (StataCorp LLC, Texas) and JMP 12.2 (SAS Institute Inc., Cary, North California).

\section{Results}

\section{Patient characteristics}

There were 1,067 patients included in this study. The mean age was 83 years (SD 8), and the age range was 65-107 years old (Table 1). The number of male patients was 627 (59\%), history of smoking was 468 (44\%), and alcohol habits was 236 (22\%). Mean body weight was 47.3 (SD 11.3), and BMI was 20.0 (SD 6.3). The 
Table 1 Patients characteristic and Univariate associations with AAD

\begin{tabular}{|c|c|c|c|c|}
\hline \multirow[t]{2}{*}{ Variable } & All $(n=1,067)$ & AAD $(n=322)$ & non-AAD ( $n=745)$ & $p$ values \\
\hline & \multicolumn{4}{|c|}{ no $(\%)$ or mean \pm SD or median [IQR] } \\
\hline Age, year & $83 \pm 8$ & $85 \pm 8$ & $83 \pm 8$ & 0.0001 \\
\hline Male & $627(59)$ & $180(56)$ & $447(60)$ & 0.21 \\
\hline Body weight, kg & $47.3 \pm 11.3$ & $45.8 \pm 10.2$ & $48.0 \pm 11.7$ & 0.005 \\
\hline Body mass index, $\mathrm{kg} / \mathrm{m}^{2}$ & $20.0 \pm 6.3$ & $19.6 \pm 3.8$ & $20.0 \pm 3.9$ & 0.12 \\
\hline History of smoking & $468(44)$ & $127(39)$ & $341(46)$ & 0.056 \\
\hline Alcohol habits & $236(22)$ & $59(18)$ & $177(24)$ & 0.045 \\
\hline \multicolumn{5}{|l|}{ ADL } \\
\hline Ambulatory & $682(64)$ & $184(57)$ & $498(67)$ & 0.003 \\
\hline Bedridden & $110(10)$ & $35(11)$ & $75(10)$ & 0.69 \\
\hline Oral nutrition & $1,018(95)$ & $304(94)$ & $714(96)$ & 0.31 \\
\hline \multicolumn{5}{|l|}{ Comorbidities } \\
\hline Diabetes mellitus & $297(28)$ & $85(26)$ & $212(29)$ & 0.49 \\
\hline Hypertension & $536(50)$ & $152(47)$ & $384(52)$ & 0.19 \\
\hline Cerebrovascular diseases & $322(30)$ & $111(35)$ & $211(28)$ & 0.045 \\
\hline Ischemic heart diseases & $146(14)$ & $44(14)$ & $102(14)$ & 0.99 \\
\hline Heart failure & $325(31)$ & $114(35)$ & $211(28)$ & 0.021 \\
\hline Chronic obstructive pulmonary diseases & $254(24)$ & $64(20)$ & $190(26)$ & 0.048 \\
\hline Chronic kidney diseases & $64(6.0)$ & $26(8.1)$ & $38(5.1)$ & 0.06 \\
\hline Dementia & $419(39)$ & $142(44)$ & $277(37)$ & 0.03 \\
\hline Cancer & $253(24)$ & $79(25)$ & $174(23)$ & 0.68 \\
\hline \multicolumn{5}{|l|}{ Vital signs } \\
\hline Body temperature, ${ }^{\circ} \mathrm{C}$ & $38.0 \pm 0.9$ & $38.0 \pm 0.9$ & $38.0 \pm 0.9$ & 0.54 \\
\hline Systolic blood pressure, $\mathrm{mmHg}$ & $150 \pm 25$ & $151 \pm 25$ & $150 \pm 25$ & 0.72 \\
\hline Diastolic blood pressure, $\mathrm{mmHg}$ & $87 \pm 17$ & $87 \pm 17$ & $87 \pm 18$ & 0.84 \\
\hline Heart rate, /min & $103 \pm 21$ & $103 \pm 22$ & $102 \pm 21$ & 0.51 \\
\hline Respiratory rate, /min & $29 \pm 7$ & $29 \pm 7$ & $29 \pm 7$ & 0.94 \\
\hline \multicolumn{5}{|l|}{ Laboratory data } \\
\hline White blood cell count, $/ \mu \mathrm{L}$ & $9,490[7,260-12,850]$ & $9,430[7,120-12,960]$ & $9,540[7,320-12,730]$ & 0.72 \\
\hline Hemoglobin, g/dL & $11.8[10.5-13.1]$ & $11.5[10.4-12.8]$ & $11.8[10.6-13.2]$ & 0.001 \\
\hline Platelet cell count, $\times 10^{4} / \mu \mathrm{L}$ & $18.9[14.7-24.2]$ & $19.2[14.9-24.4]$ & $18.8[14.7-24.1]$ & 0.63 \\
\hline Total protein, g/dL & $6.6[6.1-7.0]$ & $6.5[6.1-7.0]$ & $6.6[6.1-7.0]$ & 0.24 \\
\hline Albumin, $\mathrm{g} / \mathrm{dL}$ & $3.2[2.8-3.6]$ & $3.1[2.8-3.5]$ & $3.3[2.9-3.6]$ & 0.0008 \\
\hline Blood urea nitrogen, mg/dL & $18.7[13.8-26.5]$ & $20.0[14.7-27.6]$ & $18.2[13.5-25.7]$ & 0.01 \\
\hline Creatinine, mg/dL & $0.76[0.57-1.06]$ & $0.79[0.57-1.10]$ & $0.74[0.57-1.03]$ & 0.26 \\
\hline C-reactive protein, $\mathrm{mg} / \mathrm{dL}$ & $6.91[2.66-12.79]$ & $7.45[2.69-13.25]$ & $6.82[2.65-12.55]$ & 0.74 \\
\hline CURB65 & & & & 0.06 \\
\hline 1 & $197(18)$ & $47(15)$ & $150(20)$ & \\
\hline 2 & $461(43)$ & $132(41)$ & $329(44)$ & \\
\hline 3 & $303(29)$ & $104(32)$ & $199(27)$ & \\
\hline 4 & $102(9.6)$ & $38(12)$ & $64(8.6)$ & \\
\hline 5 & $4(0.4)$ & $1(0.3)$ & $3(0.4)$ & \\
\hline
\end{tabular}


Table 1 Patients characteristic and Univariate associations with AAD (Continued)

\begin{tabular}{|c|c|c|c|c|}
\hline \multirow[t]{2}{*}{ Variable } & All $(n=1,067)$ & AAD $(n=322)$ & non-AAD $(n=745)$ & $p$ values \\
\hline & \multicolumn{4}{|c|}{ no $(\%)$ or mean \pm SD or median [IQR] } \\
\hline \multicolumn{5}{|l|}{ Antibiotics } \\
\hline$\beta$-Lactamase inhibitors & $703(66)$ & $233(72)$ & $470(63)$ & 0.003 \\
\hline Ampicillin/sulbactam & $701(66)$ & $233(72)$ & $468(63)$ & \\
\hline Piperacillin/tazobactam & $8(0.8)$ & $4(1.2)$ & $4(0.5)$ & \\
\hline Non $\beta$-Lactamase inhibitors & $626(59)$ & $181(56)$ & $445(60)$ & 0.28 \\
\hline Ceftriaxone & $390(37)$ & $107(33)$ & $283(38)$ & \\
\hline Meropenem & $47(4.4)$ & $25(7.8)$ & $22(3.0)$ & \\
\hline Macrolides & $101(9.5)$ & $25(7.8)$ & $76(10)$ & \\
\hline Clindamycin & $35(3.3)$ & $17(5.3)$ & $18(2.4)$ & \\
\hline Levofloxacin & $31(2.9)$ & $8(2.4)$ & $23(3.1)$ & \\
\hline Others $^{\mathrm{a}}$ & $189(18)$ & $67(21)$ & $122(21)$ & \\
\hline Multiple antibiotics & $714(67)$ & $223(69)$ & $491(66)$ & 0.29 \\
\hline \multicolumn{5}{|l|}{ Drugs } \\
\hline Proton pump inhibitors & $508(48)$ & $171(53)$ & $337(45)$ & 0.02 \\
\hline Immunosuppressants & $363(34)$ & $102(32)$ & $261(35)$ & 0.29 \\
\hline Angiotensin II receptor blockers & $117(11)$ & $44(14)$ & $73(9.8)$ & 0.06 \\
\hline Angiotensin converting enzyme inhibitors & $54(5.1)$ & $15(4.7)$ & $39(5.2)$ & 0.69 \\
\hline Calcium channel blockers & $169(16)$ & $41(13)$ & $128(17)$ & 0.07 \\
\hline Beta-blockers & $98(9.2)$ & $33(10)$ & $65(8.7)$ & 0.43 \\
\hline Psychotropics & $207(19)$ & $72(22)$ & $135(18)$ & 0.11 \\
\hline Drugs for hyperuricemia & $62(5.8)$ & $22(6.8)$ & $40(5.4)$ & 0.35 \\
\hline Sputum culture & $954(89)$ & $289(90)$ & $665(89)$ & 0.81 \\
\hline Positive culture & $146(15)$ & $33(11)$ & $113(17)$ & 0.03 \\
\hline \multicolumn{5}{|l|}{ Hospital course } \\
\hline AAD & $322(30)$ & & & \\
\hline Duration until $A A D$, days & & $6[3-10]$ & & \\
\hline Duration of $A A D$, days & & $4[2-8]$ & & \\
\hline Length of hospital stay, days & $13[9-21]$ & $17[12-29]$ & $11[8-18]$ & $<0.0001$ \\
\hline Death & $88(8.2)$ & $22(6.8)$ & $66(8.9)$ & 0.27 \\
\hline
\end{tabular}

Ampicillin, Amoxicillin, Cefmetazole, Cefalexin, Cefazolin, Daptomycin, Gentamicin, Micafungin, Metronidazole, Rifampicin, Sulfamethoxazole/Trimethoprim, Vancomycin, AAD: antibiotic-associated diarrhea

number of patients who were ambulatory was 682 (64\%), bedridden was $110(10 \%)$, and on oral nutrition was $1,018(95 \%)$. The most common comorbidity was hypertension (50\%), followed by dementia (39\%), heart failure (31\%), and cerebrovascular diseases (30\%) (Table 1).

The number of patients who used $\beta$-lactamase inhibitors was $703(66 \%)$, and multiple antibiotics was 714 (67\%). The number of patients who took the sputum microbial test was 954 (89\%), of whom $146(15 \%)$ were detected bacteria (Table 2). Thus, 14\% (146/1067) were considered to have bacterial pneumonia and the rest $(86 \%)$ was aspiration or undetermined pneumonia.

\section{Factors associated with AAD}

AAD occurred in $322(30 \%)$ patients. The median duration until AAD was 6 (IQR 3,10) days, and duration of AAD was 4 (IQR 2, 8) days. Among 322 patients with AAD, Clostridium difficile antigen was positive in 14 (4.3\%) patients. The mean age was significantly higher in those who developed AAD (85 vs. 83 years, $p=$ 0.0001 ), and mean body weight and alcohol habits were significantly lower in those who developed AAD (body weight: 45.8 vs. $48.0 \mathrm{~kg}, p=0.005$; alcohol habits: $18 \%$ vs. $24 \%, p=0.045)$. The patients who were ambulatory were less likely to develop AAD $(57 \%$ vs. $67 \%, p=$ 0.003). There were no significant differences in sex, BMI, history of smoking, bedridden, and oral nutrition 
Table 2 Results of sputum culture

\begin{tabular}{|c|c|}
\hline Bacteria (Sputum) & All $(n=146) \mathrm{N}(\%)$ \\
\hline \multicolumn{2}{|l|}{ Gram negative rods } \\
\hline Haemophilus influenzae & $33(23)$ \\
\hline Haemophilus influenzae & $12(8.2)$ \\
\hline Haemophilus influenzae (BLNAR) & $21(14)$ \\
\hline Klebsiella pneumoniae & $31(21)$ \\
\hline Branhamella(Moraxella) catarrhalis & $13(8.9)$ \\
\hline Escherichia coli & $8(5.4)$ \\
\hline Escherichia coli & $5(3.4)$ \\
\hline Escherichia coli (ESBL) & $3(2)$ \\
\hline Pseudomonas aeruginosa & $7(4.8)$ \\
\hline Klebsiella oxytoca & $5(3.4)$ \\
\hline Other Gram negative rods & $10(6.9)$ \\
\hline Raoultella planticola & $4(2.7)$ \\
\hline Acinetobacter baumannii & $1(0.7)$ \\
\hline Enterobacter aerogenes & $1(0.7)$ \\
\hline Kluyvera ascorbata & $1(0.7)$ \\
\hline Pasteurella pneumotropica & $1(0.7)$ \\
\hline Proteus mirabilis & $1(0.7)$ \\
\hline Serratia marcescens & $1(0.7)$ \\
\hline \multicolumn{2}{|l|}{ Gram negative coccus } \\
\hline Neisseria & $1(0.7)$ \\
\hline \multicolumn{2}{|l|}{ Gram positive cocci } \\
\hline Staphylococcus aureus & $4(2.7)$ \\
\hline Methicillin sensitive Staphylococcus aureus & $3(2)$ \\
\hline Methicillin resistant Staphylococcus aureus & $1(0.7)$ \\
\hline Streptococcus pneumoniae & $30(21)$ \\
\hline Streptococcus pneumoniae & $29(20)$ \\
\hline Penicillin G insensitive streptococcus pneumoniae & $1(0.7)$ \\
\hline Other Streptococcus & $4(2.8)$ \\
\hline Streptococcus agalactiae (group B) & $1(0.7)$ \\
\hline Streptococcus anginosus & $1(0.7)$ \\
\hline Streptococcus group G & $2(1.4)$ \\
\hline
\end{tabular}

BLNAR $\beta$-lactamase nonproducing Ampicillin resistant, ESBL extended spectrum $\beta$-lactamase

between the patients who developed AAD and those who did not. The patients with cerebrovascular diseases, heart failure, and dementia were likely to develop AAD (cerebrovascular diseases: $35 \%$ vs. $28 \%, p=0.045$; heart failure: $35 \%$ vs. $28 \%, p=0.021$; dementia: $44 \%$ vs. $37 \%$, $p=0.03)$, and with COPD were less likely to develop AAD $(20 \%$ vs. $26 \%, p=0.048)$. There were no significant associations between other comorbidities and AAD. Median hemoglobin and albumin were significantly lower in those who developed AAD (hemoglobin: 11.5 vs. $11.8 \mathrm{~g} / \mathrm{dL}, p=0.001$; albumin: 3.1 vs. $3.3 \mathrm{~g} / \mathrm{dL}, p=$ 0.0008 ), and median blood urea nitrogen was significantly higher in those who developed AAD (20.0 vs.
$18.2 \mathrm{mg} / \mathrm{dL}, p=0.01)$. There were no significant differences in vital signs and other laboratory data between the patients who developed AAD and those who did not. There was no significant difference between the CURB 65 score and AAD. The use of $\beta$-lactamase inhibitors and PPIs was more frequent among those with AAD than their counterparts ( $\beta$-lactamase inhibitors: $72 \%$ vs. $63 \%, p=0.003$; PPIs: $53 \%$ vs. $45 \%, p=0.02$ ). There were no significant associations between other drugs and AAD among the elderly patients (Table 1 ).

The multivariate logistic regression model showed that age (OR 1.03 per year, $95 \%$ CI 1.01-1.05), $\beta$-lactamase inhibitors (OR 1.43, $95 \%$ CI 1.05-1.95), and PPIs (OR 
1.37, $95 \%$ CI 1.03-1.83) were independently associated with AAD after adjusting for other variables (Table 3).

\section{Effect of AAD on length of hospital stay and in-hospital mortality}

The median length of hospital stay was 13 (IQR 9, 21) days, and in-hospital mortality occurred in $88(8.2 \%)$ patients. The median length of hospital stay was significantly longer in those who developed AAD (17 vs. 11 days, $p<0.0001)$. However, the in-hospital mortality did not differ between those with and without AAD (6.8\% vs. $8.9 \%, p=0.27$ ).

\section{Discussion}

We explored the incidence of AAD and factors associated with AAD in elderly patients with pneumonia. The incidence of AAD was $30 \%$ among elderly patients with a mean age of 83 years. Among such patients, $\beta$ lactamase inhibitors were prescribed in $66 \%$ of patients, and $\beta$-lactamase inhibitors were significantly associated with AAD. Our study also showed the PPIs were frequently administered among elderly patients, and this class of medication was independently associated with AAD.

The incidences of AAD were lower in previous studies, which were $4.9-9.6 \%$ among hospitalized patients with a mean age of $60-68$ years $[5,11]$. The $30 \%$ incidence of AAD among inpatients in our study was much higher than those in previous studies, and the differences could partially be due to the large elderly population of our study, with a mean age of 83 years. We showed that the incidence of AAD would be elevated in an older patient population. This finding was also supported by the results of multivariate models of our study, which showed that an increase in age was significantly associated with the risk of AAD. Faced with the superaging population worldwide, the increased incidences of and preventive measures for AAD should be considered. Another explanation of higher incidence of AAD was the differences in the definition of AAD between studies. The definition of AAD was diarrhea with more than three loose or watery stools per day and this definition was as same as previous studies but the duration was at least one day in our study while two days in the previous study $[5,11]$.

Our study showed several risk and modifiable factors for AAD, namely, $\beta$-lactamase inhibitors and PPIs. Some studies found the highest frequencies of AAD in patients treated with broad spectrum penicillins, cephalosporins, and clindamycin [5, 12-14]. Wistrom et al. reported that the highest frequencies of $\mathrm{AAD}$ were found in patients treated with tazobactam, which is one of the $\beta$-lactamase inhibitors [5], but evidence about the association of $\beta$ lactamase inhibitors and AAD was scarce. We therefore classified the antibiotics based on whether they contained $\beta$-lactamase inhibitors to clarify the associations between $\beta$-lactamase inhibitors and AAD.

Several studies showed that PPIs were associated with AAD or Clostridium difficile infection with an OR of $1.98-2.90[11,15,16]$. Wong et al. reported that patients who took PPIs had a significantly higher incidence of AAD than those in the non-PPI group [17]. On the other hand, other studies reported no significant association between PPIs and Clostridium difficile infection, and some of them targeted elderly patients $[10,18,19]$. Because the association between PPIs and AAD or Clostridium difficile infection was reported, associations between PPIs and AAD in our findings should be scrutinized from the perspective of Clostridium difficile

Table 3 Multivariable regression model for AAD

\begin{tabular}{lccc}
\hline Variable & Odds ratio & 95 \% confidence interval & $\boldsymbol{p}$ values \\
\hline Age & 1.03 & $1.01-1.05$ & 0.009 \\
Body weight, $\mathrm{kg}$ & 0.99 & $0.98-1.01$ & 0.42 \\
Alcohol habits & 1.02 & $0.71-1.48$ & 0.91 \\
Ambulatory & 0.84 & $0.60-1.17$ & 0.30 \\
Cerebrovascular diseases & 1.21 & $0.89-1.64$ & 0.22 \\
Heart failure & 1.17 & $0.85-1.61$ & 0.33 \\
Chronic obstructive pulmonary diseases & 0.89 & $0.62-1.27$ & 0.50 \\
Dementia & 1.01 & $0.74-1.37$ & 0.97 \\
Hemoglobin, g/dL & 0.96 & $0.89-1.05$ & 0.40 \\
Albumin, g/dL & 0.81 & $0.61-1.09$ & 0.17 \\
Blood urea nitrogen, mg/dL & 1.01 & $0.999-1.02$ & 0.07 \\
B-Lactamase inhibitors & 1.43 & $1.05-1.95$ & 0.03 \\
Proton pump inhibitors & 1.37 & $1.03-1.83$ & 0.03 \\
\hline AAD anb & \\
\hline
\end{tabular}


infection. In addition, collagenous colitis should also be considered in patients with diarrhea on PPIs [20]. Because we defined AAD based on stool characteristics and the number of bowel movements and all enrolled patients had pneumonia, AAD might contain enteritis that was not associated with antibiotics, such as collagenous colitis.

Several potential risk factors for AAD or Clostridium difficile infection have been reported, including low ADL [11, 21], tube feeding [4, 6, 14, 22], low serum albumin $[15,23,24]$, and renal disease $[5,11$, 16, 25]. Tube feeding, low serum albumin and renal disease change the intestinal flora, and furthermore, low serum albumin provokes intestinal edemas [22, 24-27]. These mechanisms promote Clostridium difficile infection. Low ADL, tube feeding, and renal disease promote the spread of Clostridium difficile spores through care from medical staff and medical procedures [27, 28]. These factors were not independent risk factors for AAD in our study. Although these factors had weak relations with AAD in the univariate models, they were not retained in the multivariate model. Because these factors were related to each other as confounders, these factors were not retained as independent factors. On the other hand, $\beta$-lactamase inhibitors and PPIs were still independent adjusting for these factors, and our findings should be considered credible.

$\beta$-Lactamase inhibitors were used in $66 \%$ of patients, and PPIs were prescribed in $48 \%$ of patients in our study. We should be aware that many physicians tended to use antibiotics containing $\beta$-lactamase inhibitors and prescribe PPIs for elderly patients as a routine practice. We should recognize the risk of AAD due to such medications, especially in combination, and avoid the unnecessary prescription of antibiotics containing $\beta$ lactamase inhibitors and PPIs for elderly patients with pneumonia. From the perspective to avoid AAD among elder patients with pneumonia or other infectious diseases, guidelines of antibiotics choice for elder patients should be reconsidered.

Consistent with previous reports [6-8], the median length of hospital stay was significantly longer in those who developed AAD. On the other hand, there was no significant difference between the in-hospital mortality and AAD in our study. Previous studies showed that mortality was significantly higher in those who developed Clostridium difficile infection $[8,29,30]$. Because our hospital is an acute care hospital and patients with critical or terminal status tended to transfer to other facilities, our setting was not appropriate to investigate the relationship between AAD and mortality.

There were several limitations. First, our study design was retrospective, and thus we could not obtain information on all potential factors that were not recorded. Therefore, other risk factors might exist, but the information on medication use was well recorded, and the two risk factors in medication use were considered credible. Second, some cases of AAD could have been missed because medical staff could not recognize and record the stool properties and number of bowel movements for all patients. However, the electronic health record was equipped with standard form for diarrhea and the definition of diarrhea was liquid stool greater than 3 times for $24 \mathrm{~h}$ in this study. Such missed cases were less likely. In addition, such missing should be happened at random if occurred, the incidence showed the lowest data and the results of multivariable model should be credible. The length of hospital stay or inhospital mortality could also be underestimated in our study. Third, we could not take into consideration the effects of drugs that induce diarrhea, such as NSAIDs and laxatives or probiotics that prevent or reduce diarrhea. Most of elderly patients often use such drugs or probiotics, but we considered the administration of $\beta$ lactamase inhibitors or PPIs was independent to those used such drugs or probiotics. Finally, we did not discriminate the Clostridium difficile infection from AAD. Because the detection of Clostridium difficile infection at the study hospital was Clostridium difficile antigen test which was low sensitivity, the incidence of Clostridium difficile infection was underestimated. When we analyze the Clostridium difficile precisely, we should culture all stools from AAD for Clostridium difficile but this strategy was not realistic in the daily clinical practice. Therefore, we focused on AAD general in this study.

\section{Conclusions}

In elderly patients who were admitted for pneumonia, $30 \%$ developed AAD during the hospital stay, and such patients with AAD had longer hospital stays than those without AAD. The use of $\beta$-lactamase inhibitors and PPIs was significantly associated with AAD, and we should pay careful attention to the bowel symptoms in patients who were treated with $\beta$-lactamase inhibitors. The use of PPIs should be reevaluated from the perspective of AAD.

\section{Abbreviations \\ AAD: Antibiotic-associated diarrhea; BMI: Body mass index; ADL: Activities of daily living; COPD: Chronic obstructive pulmonary disease; CDK: Chronic kidney disease; PPI: Proton pump inhibitor; SD: Standard deviation; IQR: Interquartile range; OR: Odds ratio; Cl: Confidence intervals \\ Acknowledgements \\ We express appreciation to Ms. Terumi Iguni and Ms. Ai Osada, medical secretaries for performing data extraction.}

Authors' contributions

$\mathrm{YT}, \mathrm{TN}$ and TM designed the study and analyzed the datasets. YT, TN, NF, TI and JM performed the data collection. YT, TN and TM drafted the 
manuscript. NF, TI, and JM critically revised the manuscript. All authors read and approved the final manuscript.

\section{Funding}

The present study was in part supported by JSPS KAKENHI grant to TM (JP18H03032) and AMED grant to TM (JP190a0310004h0001). The funding sources had no role in the study design; collection, analysis, or interpretation of data; writing of the report; or decision to submit the manuscript for publication.

\section{Availability of data and materials}

The datasets analyzed during the current study are available from the corresponding author by request.

\section{Declarations}

\section{Ethics approval and consent to participate}

This study was approved by the Ethics Review Board of Shimane Prefectural Central Hospital (R19-022). Because all data was obtained as part of our routine daily practice, informed consent was waived by the Ethics Review Board of Shimane Prefectural Central Hospital.

\section{Consent for publication}

Not applicable.

\section{Competing interests}

No conflict interest, financial or other, exists.

\section{Author details \\ ${ }^{1}$ Department of General Medicine, Shimane Prefectural Central Hospital, Izumo, Japan. ${ }^{2}$ Department of Infectious Diseases, Shimane Prefectural Central Hospital, Izumo, Japan. ${ }^{3}$ Clinical Education and Research Center, Shimane Prefectural Central Hospital, Izumo, Japan. ${ }^{4}$ Department of Clinical Epidemiology, Hyogo College of Medicine, 1-1 Mukogawa, Hyogo 663-8501 Nishinomiya, Japan.}

\section{Received: 18 October 2020 Accepted: 28 April 2021}

\section{Published online: 17 May 2021}

\section{References}

1. Morimoto K, Suzuki M, Ishifuji T, Yaegashi M, Asoh N, Hamashige N, Abe M, Aoshima M, Ariyoshi K. The burden and etiology of community-onset pneumonia in the aging Japanese population: a multicenter prospective study. PLOS ONE. 2015;10:e0122247.

2. Mandell LA, Niederman MS. Aspiration pneumonia. N Engl J Med. 2019;380: 651-663.

3. Cornely OA, Cisneros JM, Torre-Cisneros J, Rodríguez-Hernández MJ, TallónAguilar L, Calbo E, Horcajada JP, Queckenberg C, Zettelmeyer U, Arenz D, Rosso-Fernández CM, Jiménez-Jorge S, Turner G, Raber S, O’Brien S, Luckey A. Pharmacokinetics and safety of aztreonam/avibactam for the treatment of complicated intra-abdominal infections in hospitalized adults: results from the REJUVENATE study. J Antimicrob Chemother. 2020;75:618-627.

4. Asha NJ, Tompkins D, Wilcox MH. Comparative analysis of prevalence, risk factors, and molecular epidemiology of antibiotic-associated diarrhea due to Clostridium difficile, Clostridium perfringens, and Staphylococcus aureus. I Clin Microbiol. 2006;44:2785-2791.

5. Wiström J, Norrby SR, Myhre EB, Eriksson S, Granström G, Lagergren L, Englund G, Nord CE, Svenungsson B. Frequency of antibiotic-associated diarrhoea in 2462 antibiotic-treated hospitalized patients: a prospective study. J Antimicrob Chemother. 2001;47:43-50.

6. Spencer RC. Clinical impact and associated costs of Clostridium difficileassociated disease. J Antimicrob Chemother. 1998;41 Suppl C:5-12.

7. Kyne L, Hamel MB, Polavaram R, Kelly CP. Health care costs and mortality associated with nosocomial diarrhea due to Clostridium difficile. Clin Infect Dis. 2002;34:346-353.

8. Impallomeni M, Galletly NP, Wort SJ, Starr JM, Rogers TR. Increased risk of diarrhoea caused by Clostridium difficile in elderly patients receiving cefotaxime. BMJ. 1995;311:1345-1346.

9. Loke YK, Kwok CS, Niruban A, Myint PK. Value of severity scales in predicting mortality from community-acquired pneumonia: systematic review and meta-analysis. Thorax. 2010;65:884-890.
10. Nissle K, Kopf D, Rösler A. Asymptomatic and yet C. difficile-toxin positive? Prevalence and risk factors of carriers of toxigenic Clostridium difficile among geriatric in-patients. BMC Geriatr. 2016;16:185.

11. Elseviers MM, Van Camp Y, Nayaert S, Duré K, Annemans L, Tanghe A, Vermeersch S. Prevalence and management of antibiotic associated diarrhea in general hospitals. BMC Infect Dis. 2015;15:129.

12. Haran JP, Hayward G, Skinner S, Merritt C, Hoaglin DC, Hibberd PL, Lu S, Boyer EW. Factors influencing the development of antibiotic associated diarrhea in ED patients discharged home: risk of administering IV antibiotics. Am J Emerg Med. 2014;32:1195-1199.

13. Song HJ, Kim JY, Jung SA, Kim SE, Park HS, Jeong Y, Hong SP, Cheon JH, Kim WH, Kim HJ, Ye BD, Yang SK, Kim SW, Shin SJ, Kim HS, Sung JK, Kim EY. Effect of probiotic Lactobacillus (Lacidofil ${ }^{\oplus}$ cap) for the prevention of antibiotic-associated diarrhea: a prospective, randomized, double-blind, multicenter study. J Korean Med Sci. 2010;25:1784-1791.

14. Surawicz CM, Elmer GW, Speelman P, McFarland LV, Chinn J, van Belle G. Prevention of antibiotic-associated diarrhea by Saccharomyces boulardii: a prospective study. Gastroenterology. 1989;96:981-988.

15. Southern WN, Rahmani R, Aroniadis O, Khorshidi I, Thanjan A, Ibrahim C, Brandt L. Post-surgical Clostridium difficile-associated diarrhea. Surgery. 2010;148:24-30.

16. Dial S, Delaney JA, Barkun AN, Suissa S. Use of gastric acid-suppressive agents and the risk of community-acquired Clostridium difficile-associated disease. JAMA. 2005;294:2989-2995.

17. Wong S, Jamous A, O'Driscoll J, Sekhar R, Weldon M, Yau CY, Hirani SP, Grimble G, Forbes A. A Lactobacillus casei Shirota probiotic drink reduces antibiotic-associated diarrhoea in patients with spinal cord injuries: a randomised controlled trial. Br J Nutr. 2014;111:672-678.

18. Novack L, Kogan S, Gimpelevich L, Howell M, Borer A, Kelly CP, Leffler DA, Novack V. Acid suppression therapy does not predispose to Clostridium difficile infection: the case of the potential bias. PLoS One. 2014;9:e110790.

19. Ticinesi A, Nouvenne A, Folesani G, Prati B, Morelli I, Guida L, Turroni F, Ventura M, Lauretani F, Maggio M, Meschi T. Multimorbidity in elderly hospitalised patients and risk of Clostridium difficile infection: a retrospective study with the Cumulative IIIness Rating Scale (CIRS). BMJ Open. 2015;5:e009316.

20. Mori S, Kadochi Y, Luo Y, Fujiwara-Tani R, Nishiguchi Y, Kishi S, Fujii K, Ohmori H, Kuniyasu H. Proton pump inhibitor induced collagen expression in colonocytes is associated with collagenous colitis. World J Gastroenterol. 2017;23:1586-93.

21. Rao K, Micic D, Chenoweth E, Deng L, Galecki AT, Ring C, Young VB, Aronoff DM, Malani PN. Poor functional status as a risk factor for severe Clostridium difficile infection among hospitalized older adults. J Am Geriatr Soc. 2013;61:1738-42.

22. Larentis DZ, Rosa RG, Dos Santos RP, Goldani LZ. Outcomes and risk factors associated with Clostridium difficile diarrhea in hospitalized adult patients. Gastroenterol Res Pract. 2015;2015:346341.

23. Hickson M, D'Souza AL, Muthu N, Rogers TR, Want S, Rajkumar C, Bulpitt CJ. Use of probiotic Lactobacillus preparation to prevent diarrhoea associated with antibiotics: randomised double blind placebo controlled trial. BMJ. 2007;335:80.

24. Kumarappa VS, Patel H, Shah A, Baddoura W, DeBari VA. Temporal changes in serum albumin and total protein in patients with hospital-acquired Clostridium difficile infection. Ann Clin Lab Sci. 2014;44:32-37.

25. Kim SC, Seo MY, Lee JY, Kim KT, Cho E, Kim MG, Jo SK, Cho WY, Kim HK. Advanced chronic kidney disease: a strong risk factor for Clostridium difficile infection. Korean J Intern Med. 2016;31:125-133.

26. O'Keefe SJ. Tube feeding, the microbiota, and Clostridium difficile infection. World J Gastroenterol. 2010;16:139-142.

27. Lis Ł, Konieczny A, Żłobicka K, Witkiewicz W, Hruby Z. Clostridium difficile infection in patients with end stage renal disease. Is it preventable? Przegl Epidemiol. 2020;74:11-21.

28. Durovic A, Widmer AF, Tschudin-Sutter S. New insights into transmission of Clostridium difficile infection-narrative review. Clin Microbiol Infect. 2018;24: 483-492.

29. Dubberke ER, Butler AM, Reske KA, Agniel D, Olsen MA, D'Angelo G, McDonald LC, Fraser VJ. Attributable outcomes of endemic Clostridium difficile-associated disease in nonsurgical patients. Emerg Infect Dis. 2008;14: 1031-1038.

30. Hensgens MP, Goorhuis A, Dekkers OM, van Benthem BH, Kuijper EJ. All-cause and disease-specific mortality in hospitalized patients with Clostridium difficile infection: a multicenter cohort study. Clin Infect Dis. 2013;56:1108-1116.

\section{Publisher's Note}

Springer Nature remains neutral with regard to jurisdictional claims in published maps and institutional affiliations. 